\title{
Climate effects of seasonally varying Biomass Burning emitted Carbonaceous Aerosols (BBCA)
}

\author{
G.-R. Jeong and C. Wang \\ Center for Global Change Science, Massachusetts Institute of Technology, Cambridge, MA 02139-4307, USA
}

Received: 7 March 2010 - Published in Atmos. Chem. Phys. Discuss.: 15 April 2010

Revised: 26 August 2010 - Accepted: 26 August 2010 - Published: 7 September 2010

\begin{abstract}
The climate impact of the seasonality of Biomass Burning emitted Carbonaceous Aerosols (BBCA) is studied using an aerosol-climate model coupled with a slab ocean model in a set of 60 -year long simulations, driven by BBCA emission data with and without seasonal variation, respectively. The model run with seasonally varying emission of BBCA leads to an increase in the external mixture of carbonaceous aerosols as well as in the internal mixture of organic carbon and sulfate but a decrease in the internal mixture of black carbon and sulfate relative to those in the run with constant annual BBCA emissions, as a result of different strengths of source/sink processes. The differences in atmospheric direct radiative forcing (DRF) caused by BBCA seasonality are in phase with the differences in column concentrations of the external mixture of carbonaceous aerosols in space and time. In contrast, the differences in all-sky radiative forcing at the top of the atmosphere and at the earth's surface extend beyond the BBCA source regions due to climate feedback through cloud distribution and precipitation. The seasonality of biomass burning emissions uniquely affects the global distributions of convective clouds and precipitation, indicating that these emissions have an impact on atmospheric circulation. In addition, the climate response to the periodic climate forcing of BBCA is not limited to biomass burning seasons but dynamically extends into nonbiomass burning seasons as well.
\end{abstract}

\section{Introduction}

Biomass burning emitted carbonaceous aerosols (BBCA) play an important role in the earth's radiation balance and in the hydrological cycle by absorbing and scattering sunlight

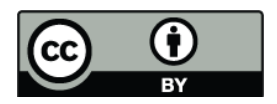

Correspondence to: G.-R. Jeong (gjeong@mit.edu) and by providing condensational nuclei for clouds (Crutzen and Andreae, 1990). The emissions of BBCA specifically become intense during the dry season in the tropics. Such a unique emission pattern causes a radiative forcing associated with BBCA that significantly varies, both geographically and seasonally.

The most recent report of the global- and annual-mean direct radiative forcing (DRF) of BBCA is estimated to be $0.03 \pm 0.12 \mathrm{~W} / \mathrm{m}^{2}$ at the top of the atmosphere (TOA) (Forster et al., 2007). However, in the tropical dry season, the regional DRF is estimated to be as high as $-5 \sim-17 \mathrm{~W} / \mathrm{m}^{2}$ (Kinne et al., 2003). Note that the negative values are due to a relatively large amount of scattering-dominated BBCA such as particulate organic matter (POM) or organic carbon (OC) rather than black carbon (BC). This regional DRF of $\mathrm{BBCA}$ is larger than the global annual mean value by two to three orders of magnitude. Such a strong DRF by BBCA over the emission source region may play a significant role in the regional and global climate.

Previous studies of BBCA have largely focused on the source region and the biomass burning seasons. Regional field experiments and modeling studies have explored the impacts of BBCA on local precipitation and clouds (Martins et al, 2009; Koren et al., 2004; Ramanathan et al., 2005; Chou et al., 2005; Lin et al., 2006; Bevan et al., 2009). Recent studies suggest that BBCA can invigorate or prohibit precipitation through microphysical effects (by increasing aerosol number concentration) or radiative effects (light absorption by BC) (Koren, 2008; Rosenfeld, 2008). In the Amazon, absorbing aerosols emitted from biomass burning were found to suppress cloud formation by heating the aerosol layer and cooling the layer below (Koren et al., 2004; Feingold et al., 2005). In Indonesia, the aerosols from a one-day biomass burning were found to significantly suppress the warm rain processes over the impact regions (Rosenfeld, 1999). This finding indicates that these effects would cause the dry atmosphere to become dryer. In contrast, analyses of satellite

Published by Copernicus Publications on behalf of the European Geosciences Union. 
observations have shown that cloud cover (high clouds) increases and stronger rainfall is induced during biomass burning in the Amazon (Lin et al., 2006). Aerosol absorption of solar radiation in the lower atmosphere can delay convective evolution but can produce higher maximum rainfall rates due to increased instability (Martins et al., 2009).

Some studies have demonstrated the significant regionalscale changes in climate variables caused by $\mathrm{BC}$ aerosols distributed global-wise (Wang, 2004; 2007). Particularly, Wang (2004) found that BC emissions cause a shift in the precipitation center in the Inter-Tropical Convergence Zone (ITCZ) and a change in the snow depth in the mid- and high- latitudes of the northern hemisphere, but no significant change in global-mean surface temperature. BC direct radiative forcing may also cause "remote climate impact", which can be very similar to the change caused by the El Nino/Southern Oscillation (ENSO) warm phase event in the tropical Pacific region (Wang, 2007). However, these studies show the seasonal anomalies in climate variables with annual constant BBCA emissions, rather than seasonally varying BBCA emissions.

Several previous studies have focused on the global impact of BBCA emissions during the dry season on changes in precipitation and clouds (Kinne et al., 2003; Menon et al., 2008; Menon, 2004; Menon and Del Genio, 2007; Rotstayn and Lohmann, 2002; Ramanathan and Carmichael, 2008). Roecker et al. (2006) investigated the impact of carbonaceous emissions on regional climate change by controlling the concentration of carbonaceous aerosols differently in mid-latitude (increase) and in low-latitude (decrease), respectively. The results show that the low-latitude surface cooling is caused primarily by the $5 \sim 60 \mathrm{~W} / \mathrm{m}^{2}$ increase in the $\mathrm{BC}$ absorption of solar radiation. This finding is similar to those of previous observational and modeling studies $(\mathrm{Kr}-$ ishnan and Ramanathan, 2002; Menon et al., 2002). These studies all suggest that less surface solar radiation and associated surface cooling caused by $\mathrm{BC}$ result in less evaporation but more soil moisture; these phenomena occur all year long and lead to more rainfall during the wet seasons. These studies reveal seasonal changes in climate variables. However, the global and seasonal climate effects due to the seasonality of BBCA emissions and seasonal radiative forcing have not been well understood.

In this study, we investigate how the seasonally varying DRF of BBCA, which is heterogeneously distributed forcing, could affect climate systems when feedbacks particularly from clouds and precipitation are considered. The interactive aerosol-climate model used in this study, along with the model configuration and methodology, are described in the next section, followed by the description and discussions of our major results. The conclusions will be drawn in the last section.

\section{The model and configuration}

In order to determine the effects of seasonally varying climate forcing, we prepared two sets of emission data: seasonal emission and non-seasonal emission. The seasonal biomass burning emission of carbonaceous aerosols was prepared based on the monthly biomass burning BC data of the Global Emission Inventory Activities, version 1 (GEIA v1; http://www.geiacenter.org). This is a climatological data set in which the seasonality of biomass burning emission is produced by the modification of the data of Hao et al. (1990), the assumptions of extra-tropical forest fires in the summertime, and the comparison of vegetation fires in Africa with the Advanced Very High Resolution Radiometer (AVHRR) images (Cook et al., 1996). The global distribution was completed by using a three-dimensional chemical transport model (CTM) (Cook and Wilson, 1996). The OC biofuel emission was derived by scaling the biofuel $\mathrm{BC}$ emission by a factor of six (Bond et al., 2004). Note that there are several annually varying estimations of biomass burning emissions available, including the Global Fire Emissions Database (GFED; e.g., Van der Werf et al., 2006), derived by using timely varying satellite fire retrievals, and REanalysis of the TROpospheric chemical composition (RETRO; Schultz et al., 2008), derived by using vast literature about country level-burned area with recent satellite observations (Along Track Scanning Radiometer, or ATSR fire pixel). In this study, however, we address the issue of climate effects associated with seasonality rather than inter-annual variability of BBCA emissions.

For the non-seasonal emission, constant BBCA emissions derived based on the annual mean were adopted for each month. The same fossil fuel emissions were used in both emission sets. The fossil fuel emissions were derived from the MIT Emission Prediction and Policy Analysis Model (EPPA; Paltsev et al., 2005) and are constant across different months. The annual BC and $\mathrm{OC}$ emissions are $6.1 \mathrm{Tg} / \mathrm{yr}$ and $36.9 \mathrm{Tg} / \mathrm{yr}$ for the biofuel emissions, and $8.6 \mathrm{Tg} / \mathrm{yr}$ and $20.8 \mathrm{Tg} / \mathrm{yr}$ for the fossil fuel emissions, respectively. Figure 1 shows the seasonal biomass burning $\mathrm{BC}$ emissions along with annual-mean fossil fuel and biomass burning emissions of carbonaceous aerosols. The regions with the highest emission levels of fossil fuel carbonaceous aerosols are in China and India, followed by Europe, the eastern US, and central Africa.

The major BBCA sources include tropical Africa, South America, Siberia, and South Asia. The emissions have strong seasonality, appearing in the southern part of Africa and the southern part of South America, South Asia, and Siberia in boreal summer (June-July-August, JJA), and the north side of the ITCZ in Africa and the far north of South America in boreal winter (December-January-February, DJF). In boreal fall (September-October-November, SON), the emissions gradually disappear from the equator in Africa and South America, while the winter emissions begin emerging 
(a)

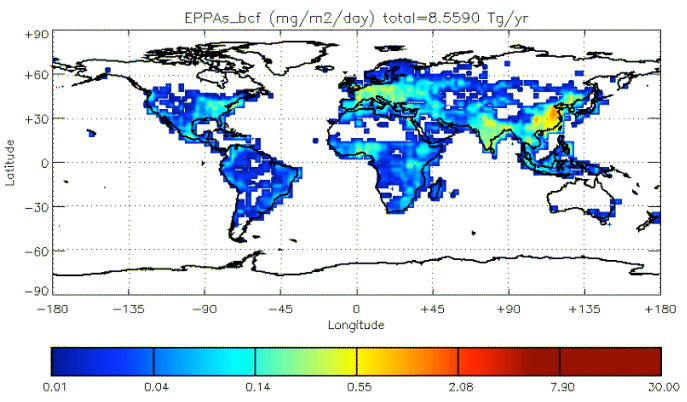

(c)

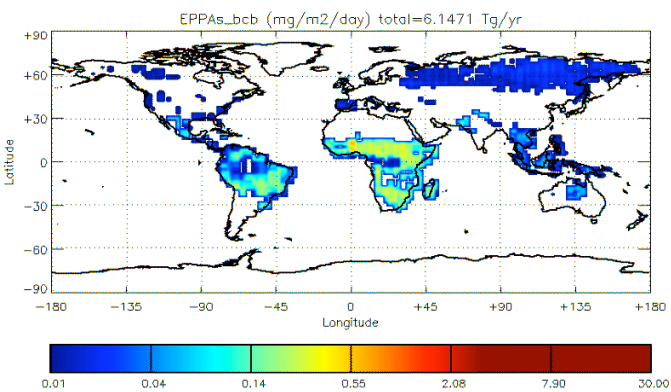

(e)

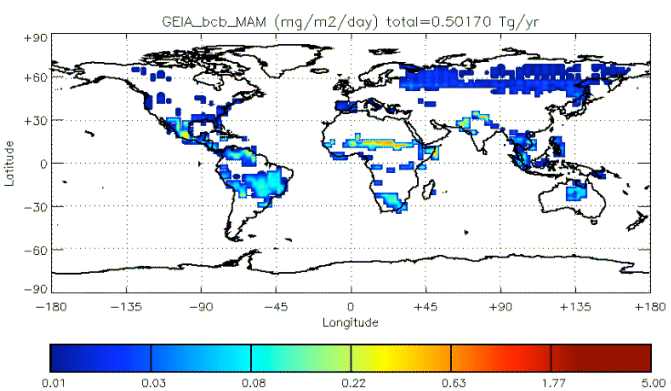

(g)

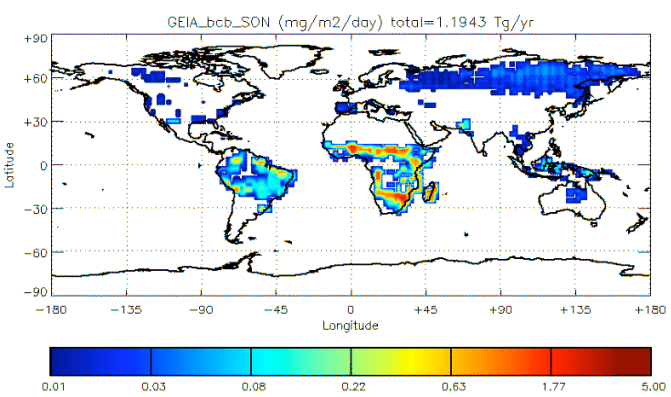

(b)

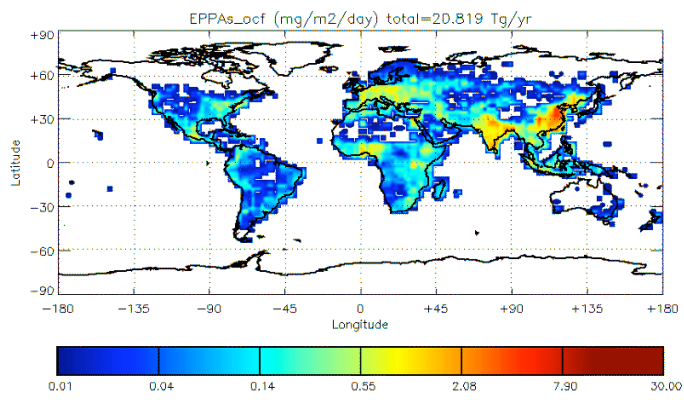

(d)

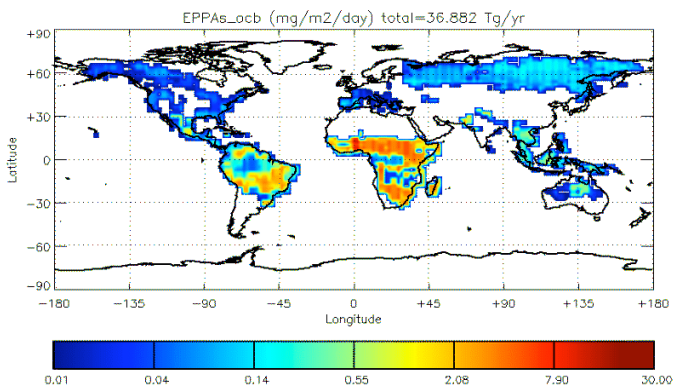

(f)

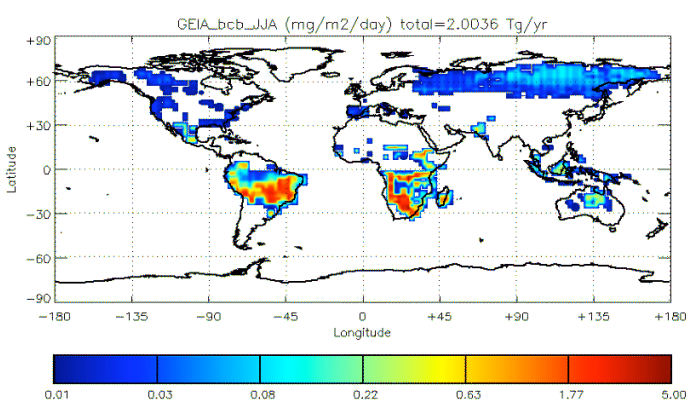

(h)

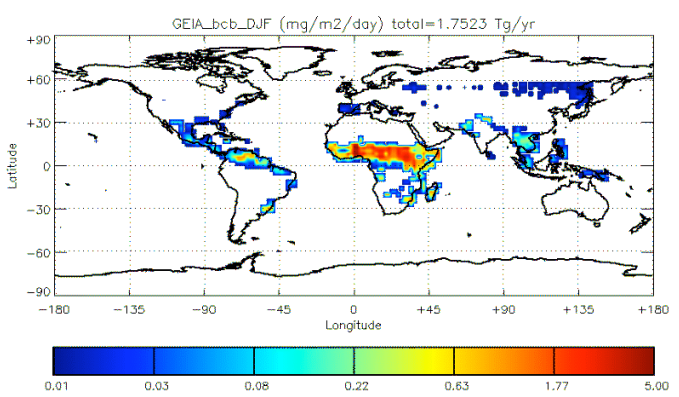

Fig. 1. Global distribution of annual emissions of fossil fuel (a) BC and (b) OC as well as biomass burning (c) BC and (d) OC. Also shown are global distributions of seasonal emissions of biomass burning BC in: (e) March-April-May (MAM), (f) June-July-August (JJA), (g) September-October-November (SON), and (h) December-January-February (DJF). 
from the north part of Africa. In other words, BBCA emission regions migrate over Africa and South America from season to season except in boreal spring (March-April-May, MAM). The global means of seasonal BBCA emissions of $\mathrm{BC}$ are $0.50 \mathrm{Tg} / \mathrm{yr}, 2.00 \mathrm{Tg} / \mathrm{yr}, 1.19 \mathrm{Tg} / \mathrm{yr}$, and $1.75 \mathrm{Tg} / \mathrm{yr}$ in boreal spring, summer, fall, and winter, respectively. The global means of seasonal biomass burning OC emissions are $3.01 \mathrm{Tg} / \mathrm{yr}, 12.02 \mathrm{Tg} / \mathrm{yr}, 7.17 \mathrm{Tg} / \mathrm{yr}$, and $10.51 \mathrm{Tg} / \mathrm{yr}$ in boreal spring, summer, fall, and winter, respectively. Therefore, the emissions of BBCA in the seasonal run are lower than the values in the non-seasonal run in boreal spring and fall but higher in boreal summer and winter. On the other words, the non-seasonal data set underestimates the BBCA emissions in boreal summer and winter but overestimates in boreal spring and fall.

These carbonaceous emissions were fed into a threedimensional interactive aerosol-climate model developed based on the Community Atmospheric Model version 3 (CAM3) of the National Center for Atmospheric Research (NCAR) (Kim et al., 2008). Its aerosol module describes size- and mixing state-dependent physiochemical and hygroscopic processes of seven aerosol modes using a twomoment scheme. These modes include the main anthropogenic aerosols separated based on size, composition, and mixing state, including external mixture of $\mathrm{BC}$, external mixture of $\mathrm{OC}$, three modes of external sulfate (nucleation, Aitken, and accumulation mode), one internal mixture of BC as the core and sulfate as the shell (MBS), and one internal mixture of OC and sulfate in homogeneous mixing (MOS). Each of these modes has a prognostic size distribution. The model results were compared with satellite, surface, and aircraft measurements (e.g., Kim et al., 2008; Wang et al., 2009). The aerosol module fully interacts with CAM 3 . The prediction of aerosol module is driven by CAM3 predicted variables such as temperature, humidity, pressure, wind, as well as cloud and precipitation in the CAM3 time step. When an option is selected, the aerosol properties predicted by the aerosol module are used in the radiation module of CAM3 to calculate the atmospheric radiative budget and thus to affect climate dynamics. For details on the model and model performance versus observations, see Kim et al. (2008) and Wang et al. (2009). In this study, the aerosol radiative forcing includes only the direct radiative forcing (DRF) of aerosols and not the aerosol indirect radiative forcing. Detailed description of the performance of CAM3 in simulating physical and dynamical processes can be found in Collins et al. (2006), Boville et al. (2006), Hurrell et al. (2006), and Hack et al. (2006).

Two sets of simulations were conducted in this study, each having two model runs using the seasonal and non-seasonal carbonaceous emissions, respectively. In the first set of runs, aerosol properties predicted by the aerosol module were not used in the radiation module of CAM3; thus, the interaction between aerosol and climate is only one-way (aerosol module is still driven by CAM3 dynamics and physics predic- tion). The useful feature of this set of runs is the ability to derive the radiative forcing of BBCA without disturbing the climate state. The radiative forcing was derived by calling the radiation module twice at each time step: with and without aerosol loading. The difference in radiative fluxes resulting from these two calls indicates the radiative forcing of aerosols. The radiative profile derived from the second call, i.e., the one without aerosol loading, was actually used in the climate model. This set is hereafter called the offline runs. In the second set of simulations, the aerosol module and CAM3 were fully interactive, i.e., not only was the aerosol module driven by the climate model, but the predicted aerosol properties were also used in the CAM3 radiation module; thus, the feedback of climate dynamics to aerosol forcing was included. This set will be referred to as the online runs. The offline runs lasted 5 years and were driven by observed climatological sea surface temperature. We used the last 3-year means of modeled results in analyses unless otherwise indicated. In the online runs, the model was coupled to a slab ocean model and the integration times were 60 years to reach equilibrium. The last 20 -year means of the results were used in our analyses.

The effects of seasonality of BBCA on aerosol direct radiative forcing (DRF) and on climate were isolated by comparing the results of two runs, in either the offline or online set, each with and without seasonal BBCA emissions, respectively, i.e.,

$\Delta c=c_{\text {seasonal }}-c_{\text {non-seasonal }}$

Where $c$ is a given quantity (aerosol DRF or other variables), and $c_{\text {seasonal }}$ and $c_{\text {non-seasonal }}$ represent the results of the run using seasonal and non-seasonal BBCA emissions, respectively. $\Delta c$ refers to the difference as the "effect of BBCA seasonality on c." For instance, $\triangle \mathrm{DRF}$ indicates the differences in DRF of seasonal BBCA emissions relative to DRF of non-seasonal BBCA emissions.

\section{Results}

\subsection{Global means of aerosol direct radiative forcing}

Given the two sets of biomass burning carbonaceous aerosol data for each model configuration (online and offline), the direct radiative forcing (DRF) and the differences in DRF due to emission seasonality $(\triangle \mathrm{DRF})$ were examined after implementing the 5-year offline runs and 60-year interactive runs, respectively. Note again that the "forcing" derived from the online runs includes climate feedback to the aerosol effect and therefore is not the forcing defined in the Intergovernmental Panel on Climate Change (IPCC) 2001 (Ramaswamy et al., 2001). This study does not consider the indirect effects of aerosols (the change in cloud properties caused by alteration in activated aerosol number concentration - the microphysical path). Therefore, all the cloud changes presented 
Table 1. Values of Direct Radiative Forcing (DRF) in seasonal emissions and differences in DRF due to seasonal BBCA emissions (offline runs). Top two rows show all-sky values; bottom two rows show clear-sky values.

\begin{tabular}{llrrrrr}
\hline & & MAM & JJA & SON & DJF & Ann \\
\hline Values of DRF & TOA_all-sky & -0.237 & -0.176 & -0.122 & 0.101 & -0.109 \\
in seasonal BBCA emission & Surface_all-sky & -1.557 & -2.445 & -1.880 & -1.960 & -1.961 \\
$\left(\mathrm{~W} / \mathrm{m}^{2}\right)$ & Atmosphere_all-sky & 1.320 & 2.269 & 1.758 & 2.061 & 1.852 \\
& & & & & & \\
Fractional changes in DRF & TOA_all-sky & 464.5 & 0.5 & 196.7 & -729.7 & 58.3 \\
relative to non-seasonal & Surface_all-sky & -19.9 & 7.2 & -5.9 & 21.3 & 0.0 \\
Emission (\%) & Atmosphere_all-sky & -30.6 & 7.8 & -10.2 & 28.9 & -2.1 \\
& & & & & & -0.861 \\
Values of DRF & TOA_clear-sky & -0.842 & -1.138 & -0.862 & -0.599 & -2.615 \\
in seasonal BBCA emission & Surface_clear-sky & -2.093 & -3.270 & -2.508 & -2.589 & -2.61 .754 \\
(W/m $\left.{ }^{2}\right)$ & Atmosphere_clear-sky & 1.250 & 2.132 & 1.646 & 1.990 & 1.754 \\
& & & & & & -0.5 \\
Fractional changes in DRF & TOA_clear-sky & 5.7 & 1.3 & 2.6 & -9.2 & -1.2 \\
relative to non-seasonal & Surface_clear-sky & -18.9 & 6.1 & -5.8 & 18.7 & -1.7 \\
Emission $(\%)$ & Atmosphere_clear-sky & -29.9 & 8.9 & -9.7 & 30.9 & \\
\hline
\end{tabular}

Where, TOA indicates the top of the atmosphere.

Table 2. Same as Table 1, except for online runs.

\begin{tabular}{llrrrrr}
\hline & & MAM & JJA & SON & DJF & Ann \\
\hline Values of DRF & TOA_all-sky & -0.647 & -0.102 & -0.113 & -0.104 & -0.241 \\
in seasonal BBCA emission & Surface_all-sky & -1.733 & -1.867 & -1.491 & -1.804 & -1.724 \\
$\left(\mathrm{~W} / \mathrm{m}^{2}\right)$ & Atmosphere_all-sky & 1.086 & 1.765 & 1.376 & 1.701 & 1.482 \\
& & & & & & \\
Fractional changes in DRF & TOA_all-sky & 547.0 & -62.4 & -71.0 & 33.3 & 15.3 \\
relative to non-seasonal & Surface_all-sky & 1.8 & -6.4 & -25.6 & 38.0 & -1.7 \\
Emission (\%) & Atmosphere_all-sky & -32.3 & 2.5 & -14.8 & 38.1 & -4.0 \\
& & & & & & \\
Values of DRF & TOA_clear-sky & -1.003 & -1.163 & -0.986 & -0.889 & -1.010 \\
in seasonal BBCA emission & Surface_clear-sky & -1.919 & -2.739 & -2.228 & -2.470 & -2.338 \\
(W/m $\left.{ }^{2}\right)$ & Atmosphere_clear-sky & 0.918 & 1.577 & 1.245 & 1.581 & 1.330 \\
& & & & & & -3.0 \\
Fractional changes in DRF & TOA_clear-sky & 2.3 & -2.7 & -0.7 & -9.8 & -3.1 \\
relative to non-seasonal & Surface_clear-sky & -19.7 & 0.6 & -7.8 & 16.1 & -3.1 \\
Emission $(\%)$ & Atmosphere_clear-sky & -34.9 & 3.1 & -12.3 & 38.6 & -3.2 \\
\hline
\end{tabular}

in this paper were caused by the direct radiative effects of aerosols through changes in dynamical processes and circulation patterns.

DRF and $\triangle \mathrm{DRF}$ in global seasonal and annual means derived from the offline runs and the online runs are shown in Table 1 and Table 2, respectively. In the offline runs, the seasonality of BBCA emission enhanced the negative forcing of global annual means of $\triangle \mathrm{DRF}$ at the top of the atmosphere (TOA) by $58 \%$, which is much larger than global annual means of $\triangle \mathrm{DRF}$ at surface and in the atmosphere. This implies that including the seasonality of BBCA compared to the case otherwise would further cool the earth's ra- diation system. The global seasonal means of $\triangle \mathrm{DRF}$ at TOA demonstrate that this relative "cooling" in the annual base largely comes from the enhanced negative forcing in boreal spring (by a factor of +4.6) and fall (+1.9), where the BBCA emissions in the seasonal runs were actually much lower than those in the non-seasonal runs. In two other seasons when BBCA emissions in the seasonal runs were clearly higher than those in non-seasonal runs, the negative TOA forcing was much weakened, e.g., in boreal winter by a factor of +7.3 and even changed the sign of DRF at TOA. These contrasting features clearly show that BC aerosols from biomass emissions, especially in boreal winter, play an important role in 
(a)

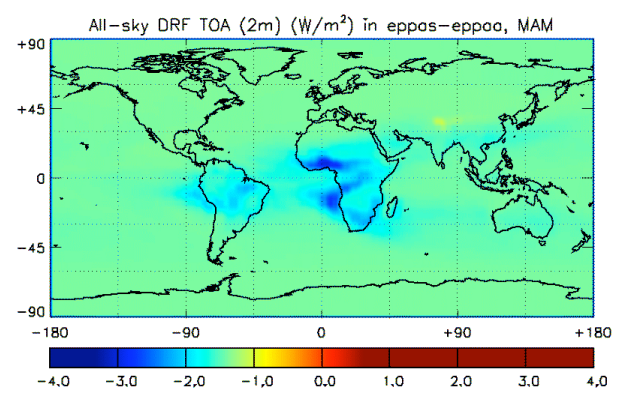

(c)

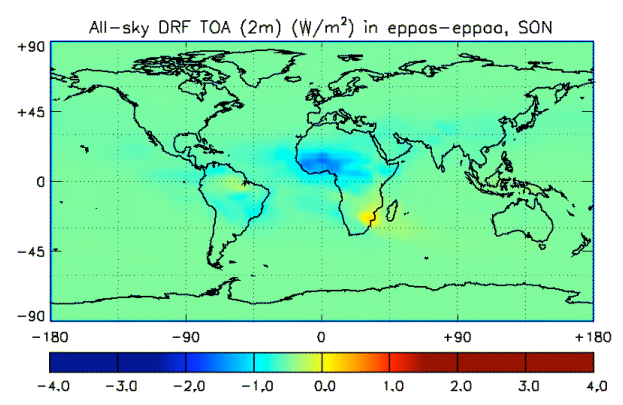

(b)

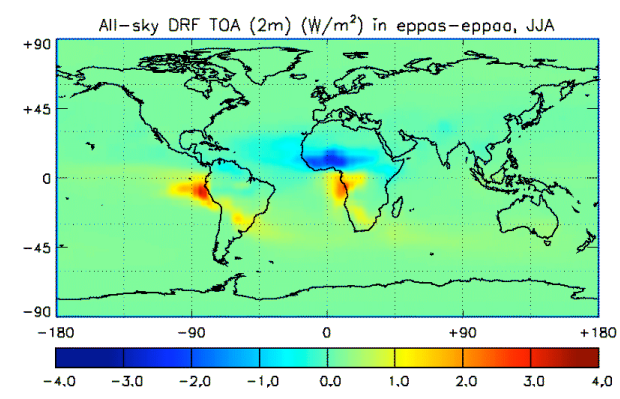

(d)

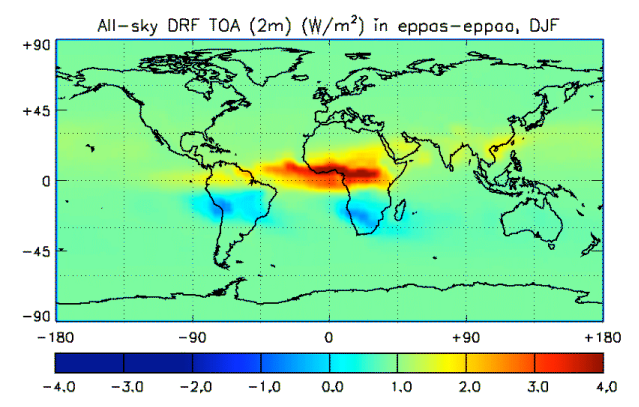

Fig. 2. Differences in aerosol direct radiative forcing (DRF) in $\mathrm{W} / \mathrm{m}^{2}$ at top of the atmosphere (TOA) due to the seasonality of BBCA emissions in offline runs; shown as means over the months of: (a) MAM, (b) JJA, (c) SON, and (d) DJF.

warming the Earth-atmosphere system, while the aerosols in non-biomass burning season contribute to the cooling of the system. Such a large difference in seasonal means of all-sky DRF is also clearly shown in the global distribution of $\triangle \mathrm{DRF}$ at TOA (Fig. 2). The negative $\triangle \mathrm{DRF}$ at TOA is distinct in biomass burning source regions in boreal spring and fall, and in boreal summer and winter over regions where biomass burning occurs in spring, all clearly attributed to negative differences in BBCA loading in the seasonal runs comparing to the non-seasonal runs. The positive $\triangle \mathrm{DRF}$ at TOA is dominant in the equatorial regions of Africa and South America during boreal winter, and in the west sea of South America and Africa during boreal summer. These patterns of $\triangle \mathrm{DRF}$ at TOA reflect the patterns of aerosol column concentrations resulting from the seasonality of BBCA emissions (high in winter and very low in spring). More importantly, these patterns indicate the cloud effect of BBCA on DRF because, for the same set of runs, clear-sky $\triangle \mathrm{DRF}$ values do not display such a large relative difference. Note that the large fraction of OC in BBCA may greatly increase the single scattering albedo of aerosol bulk and thus lead to a more negative TOA forcing.

In the online runs, the all-sky DRF at TOA in the global annual mean is $-0.24 \mathrm{~W} / \mathrm{m}^{2}$, which is more cooling than in the offline runs. However, its fractional change relative to non-seasonal emission is enhanced by about $15.3 \%$, which is a smaller change than in the offline runs. In addition, the seasonal changes in the all-sky DRF in online runs are different from those in the offline runs. In all seasons, all-sky DRFs at TOA are negative. In spring (non-biomass burning season) and in boreal winter the negative DRF at TOA is enhanced, while it is weakened in boreal summer and fall. It is noteworthy that seasonality of BBCA emissions in the online runs enhances the negative DRF at TOA in boreal spring (non-biomass burning season) by a factor of 5.47, whereas it leads to smaller changes in the DRF at TOA in biomass burning seasons - a factor of $-0.71 \sim+0.33-$ when compared with the one in the offline runs. It is worthy reiterating that these "forcings" derived in the online runs are actually responses that include feedbacks. It is thus understandable that some of the features differing from the offline run results (where the climate dynamics was not interrupted by aerosol forcings) could be well attributed to the feedbacks (see also later discussions).

\subsection{Global distribution of aerosol loading and direct radiative forcing}

Figure 3 shows the global distributions of annual mean of the differences in the column loading of external BC and $\mathrm{OC}$ as well as their internal mixtures with sulfate, i.e., BC-sulfate internal mixture (MBS) and OC-sulfate internal 
(a)

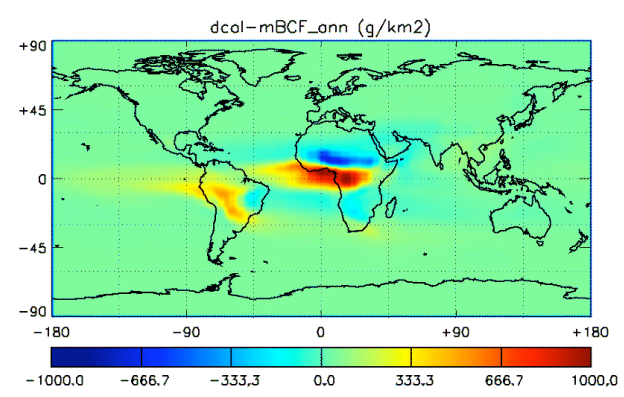

(c)

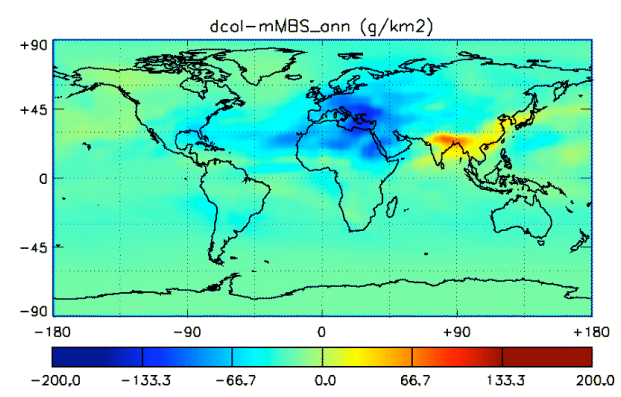

(b)

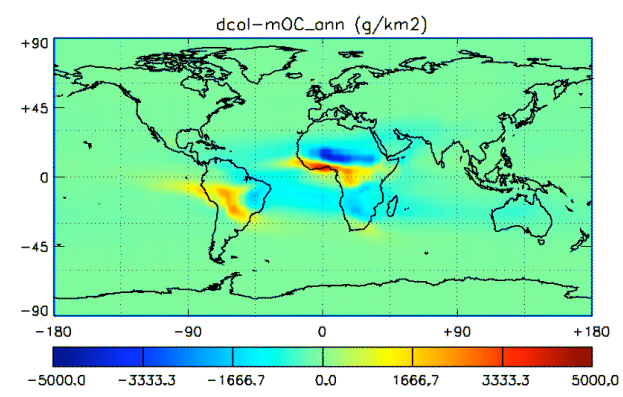

(d)

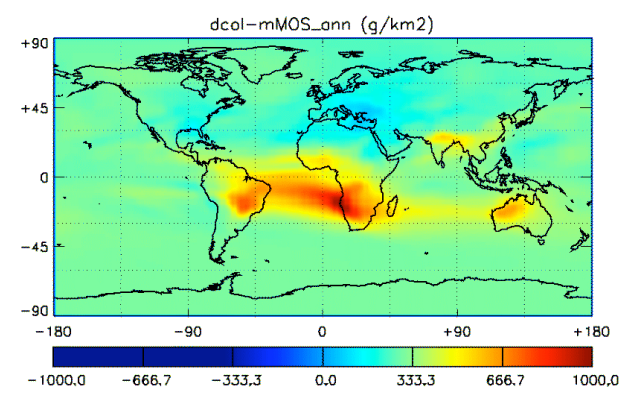

Fig. 3. Global distributions of differences in annual column loading $\left(\mathrm{g} / \mathrm{km}^{2}\right)$ due to seasonal BBCA emissions in online run of: (a) BC, (b) OC, (c) BC-sulfate mixture (MBS), and (d) OC-sulfate mixture (MOS).

mixture (MOS), due to the seasonality of BBCA emissions. The large magnitudes of the differences in column loadings of the external carbonaceous aerosols are concentrated on the aerosol source regions. For instance, the largest magnitudes of $\triangle \mathrm{BC}$ and $\triangle \mathrm{OC}$ appear over South America and Africa. In contrast, the effect of the seasonality of BBCA emissions on MBS and MOS is found distant from the aerosol source regions, reflecting a difference in the life cycles of various aerosols (the mixtures are formed through chemical aging of external aerosols in our model). For the mixtures, $\triangle \mathrm{MBS}$ is clearly negative over northern Africa, southern Europe, and the Atlantic Ocean but positive over India, the Tibetan Plateau, and the east coast of Asia. The increase in $\triangle \mathrm{MOS}$ dominates over most biomass source regions and, most importantly, clearly extends to the downwind regions. The differences in column loading of internal mixtures due to the seasonality of biomass emissions, such as $\triangle \mathrm{MBS}$ and $\triangle \mathrm{MOS}$, are about $40 \%$ of the differences in column loading of external carbonaceous aerosols, $\triangle \mathrm{BC}$ and $\triangle \mathrm{OC}$, respectively. In addition, the effects of the seasonality of BBCA emissions on $\mathrm{OC}$ and MOS are much larger than those on BC and MBS: by a factor of 5 .

On a global-mean basis, the seasonality of BBCA leads to an annual increase in column loading of external BC (12\%) and $\mathrm{OC}(9 \%)$ as well as mixture MOS $(6 \%)$ but a reduction of MBS $(-2 \%)$. The increase in external carbonaceous aerosols
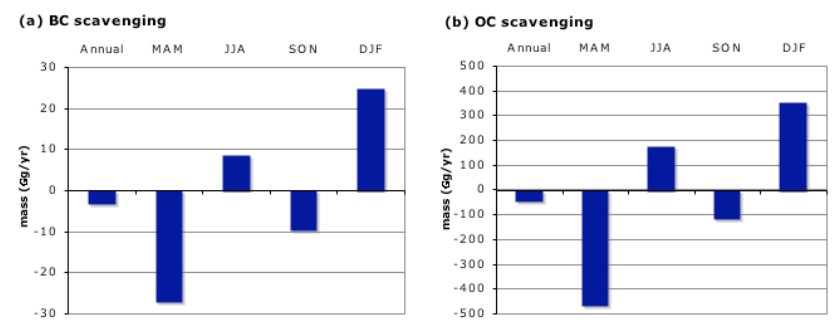

(c) MBS aging

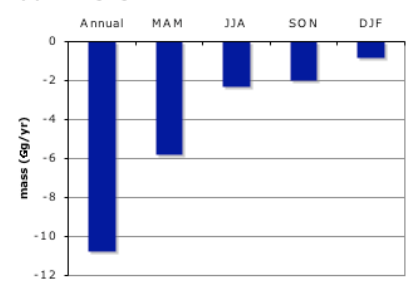

(d) MOS aging

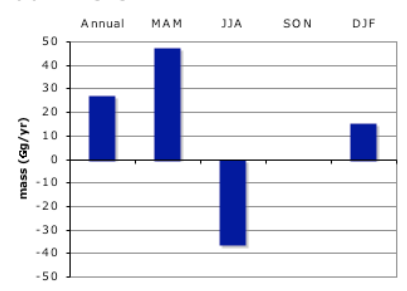

Fig. 4. Differences in annual and seasonal mean aerosol mass budget $(\mathrm{Gg} / \mathrm{yr})$ due to scavenging of external mixtures of (a) BC and (b) $\mathrm{OC}$, and the aging of internal mixtures of (c) MBS and (d) MOS.

is largely due to the relative dryness during the biomass burning seasons. In our analysis, we find the additional emissions in the seasonal biomass emission run (i.e., boreal summer and winter) clearly exceed the added scavenging in a relative sense (Fig. 4a, b). Note that in spring (non-biomass 
(a) $\mathrm{BC}$

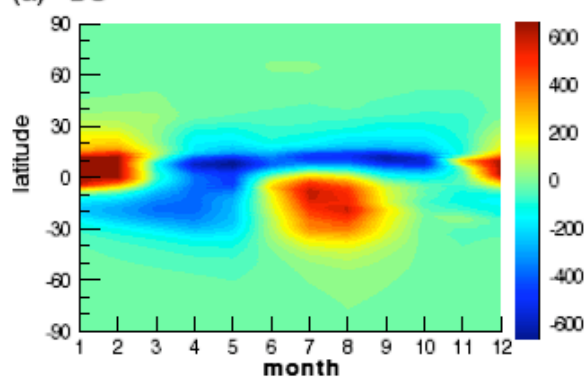

(c) MBS

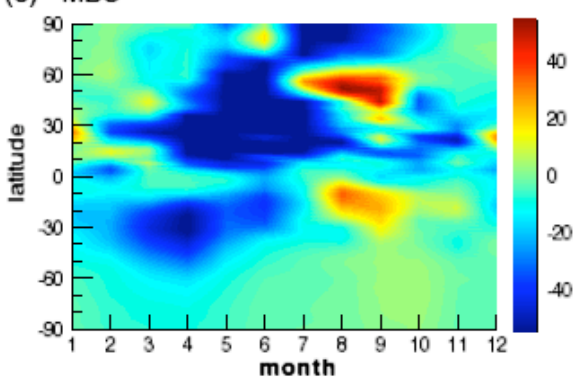

(b) $\mathrm{OC}$

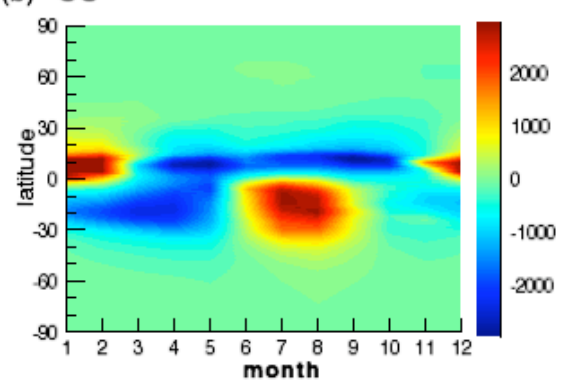

(d) MOS

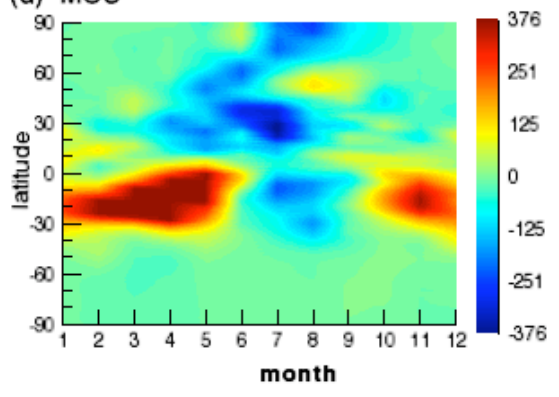

Fig. 5. Hovmöller diagram of zonal monthly means of differences in column loading $\left(\mathrm{g} / \mathrm{km}^{2}\right)$ due to seasonal BBCA emissions in online runs of: (a) BC, (b) OC, (c) MBS, and (d) MOS.

burning season), the difference in scavenging of external carbonaceous aerosols is purely the result of greatly reduced emissions in the seasonal-BBCA run. The opposite sign in the difference in MOS and MBS column loading is the result of enhanced aging of OC from the secondary production of biogenic volatile organic compounds (BVOC) (Kim et al., 2008), specifically during the non-biomass burning season of boreal spring and, to a less extent, in late fall (Fig. 4c, d). These kinds of secondary organic matters simply fill in the positions held by BBCA in the constant emission run and thus lead to greatly enhanced aging for MOS and, through consequent transformation, to an increase in MOS column loading. Therefore, different source strengths of BBCA emissions lead to different transformation and sink processes.

When presented in the format of a Hovmöller diagram (Fig. 5), the zonal and monthly means of $\triangle B C$ and $\triangle O C$ directly reflect the seasonality of BBCA emissions. However, the patterns of $\triangle \mathrm{MOS}$ and $\triangle \mathrm{MBS}$ clearly spread across both temporal and spatial scales, extending well into nonbiomass burning seasons and regions. Interestingly, the effect of the seasonality of BBCA emissions also extends to the atmospheric abundance of sulfate aerosols as well as gaseous sulfuric acid (not shown), mostly through the changes in carbonaceous aerosol constituents, although with complicated patterns. It can be seen that the limited availability of sulfuric acid gases in winter causes the decrease in MBS and MOS in this biomass-burning season. However, in the spring and late fall, MOS exhibits an increase in column loading, largely due to the above-discussed effect of secondary OC from BVOC.

We find that the effects of seasonality of BBCA emissions are very clear in even annual mean distributions of radiative forcing of aerosols (Fig. 6). In the offline runs that excluded the climate responses to the aerosol forcing, the distributions of $\triangle \mathrm{DRF}$ are mainly concentrated over the biomass regions, though with clear spreading toward the downwind areas, particularly in the atmospheric and surface forcing, suggesting the effect of absorbing aerosols (Fig. 6a, c, e). These results generally reflect the effect of BBCA aerosols along their transport paths in the atmosphere. When the climate responses are included, e.g., in the online runs, the distributions of $\triangle \mathrm{DRF}$ at TOA and surface are very complicated and different from those in the offline runs, reflecting in particular the cloud cover changes forced by the aerosol DRF (Fig. 6b, d) as well as the enhancement/reduction of such forcing due to cloud cover changes below the absorbing aerosol layer (e.g., Kim et al, 2008).

The pattern of atmospheric $\triangle \mathrm{DRF}$ (Fig. 6f) derived from the online runs is similar to that of the offline runs. This is because such forcing is a direct result of the thermodynamic heating of absorbing aerosols. The evidence of the aerosol-climate interaction in the online runs is also shown in the zonal and monthly mean of $\triangle \mathrm{DRF}$ (Fig. 7). The online forcing (including the feedback) again displays a much more complicated seasonality pattern at TOA and at the surface, compared to the offline results that represent the changes in conventionally defined aerosol radiative forcing that peak in 
(a)

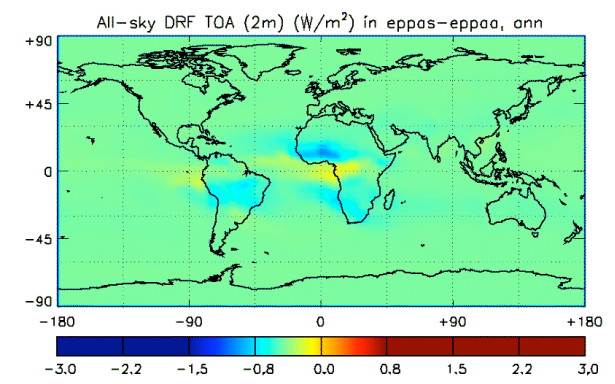

(c)

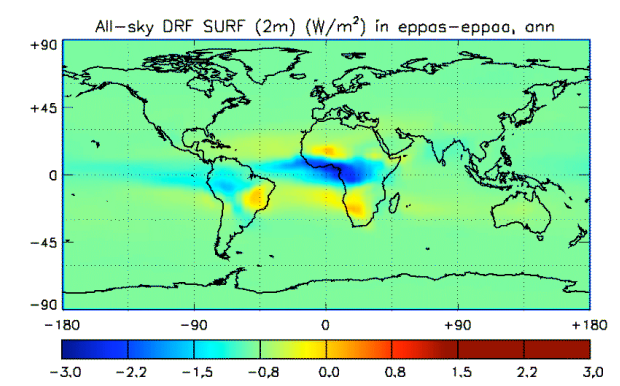

(e)

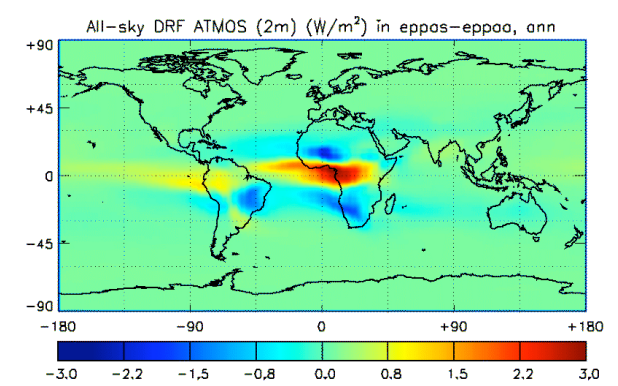

(b)

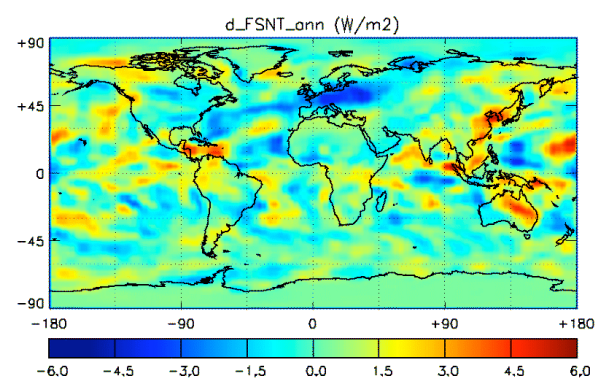

(d)

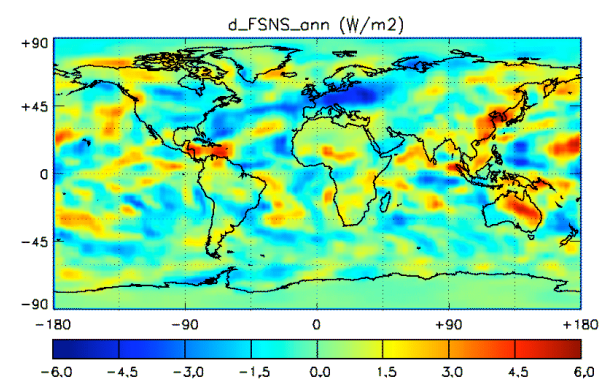

(f)

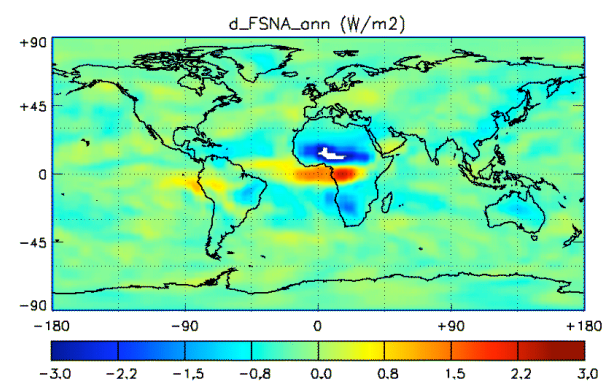

Fig. 6. Comparison of global distribution of differences in annual DRF $\left(\mathrm{W} / \mathrm{m}^{2}\right)$ caused by seasonality of BBCA emissions derived from the offline (the left column) and online runs (the right column) at the top of the atmosphere (a and $\mathbf{b}$ ), at the surface (c and d), and in the atmosphere (e and f), respectively.

summer over the southern hemispheric tropics and subtropics and in spring and winter over the northern hemispheric tropics and subtropics. This finding indicates that the aerosol direct effects due to the seasonality of BBCA last longer than the biomass burning seasons and extend to regions beyond the biomass burning areas. These results imply that the effect of the seasonality of BBCA emissions may last much longer than the biomass-burning seasons and, with the evolution of large-scale dynamics, may create a long-lasting climate effect.

\subsection{Climate responses}

Under these seasonally varying climate forcing and mass budgets, we investigate corresponding climate responses with feedback. We concentrate our analysis on variables that have been identified to be affected significantly by the DRF of aerosols in previous works (e.g., Wang, 2004), including convective cloud cover and precipitation. The differences in climate variables between the model runs with and without the seasonality of BBCA emissions are examined by using the student $t$-test for the modeled results for the last 20 years. All the results discussed here are statistically significant with a significance level of 0.1 unless otherwise indicated.

The distributions of annual means of the difference in cloud cover due to the seasonality of BBCA are shown in Fig. 8. The change in total cloud cover is significant both in statistical and relative terms, approaching a relative difference of $10 \%$ in many places (Fig. 9). The global annual mean of the difference in total cloud fraction is $1.2 \times 10^{-4}$, which is smaller than the differences in each level of cloud fraction, such as low-level clouds $\left(\triangle \mathrm{CLDLOW}, 6.0 \times 10^{-4}\right)$, 
(a) DRF at the top of atmosphere (offline)

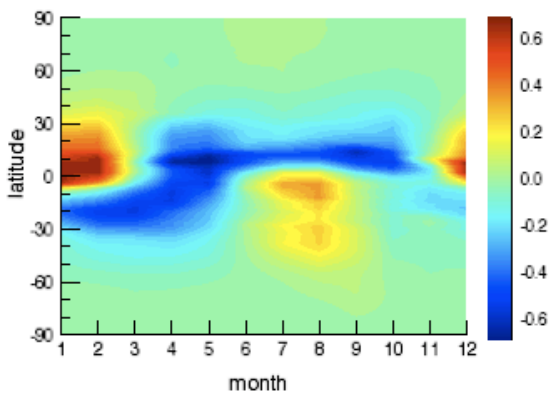

(c) DRF at the surface (offline)

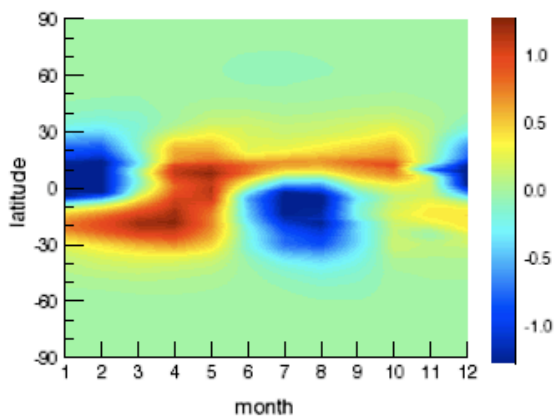

(e) DRF in the atmosphere (offline)

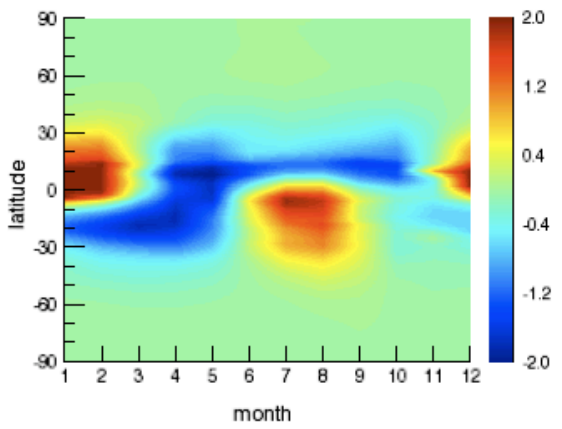

(b) DRF at the top of atmosphere (online)

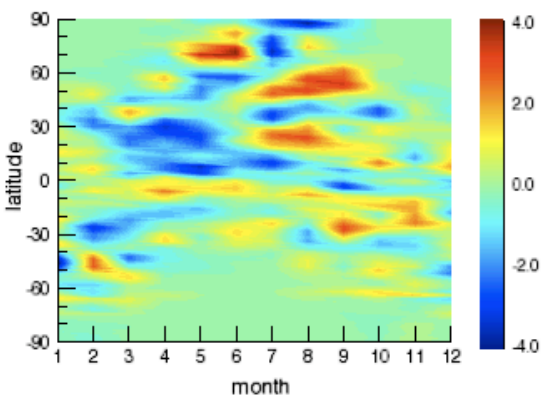

(d) DRF at the surface (online)

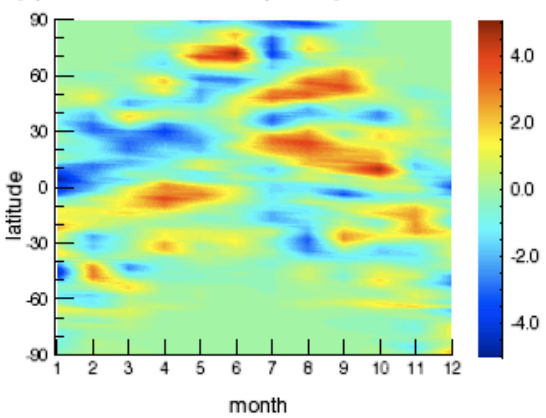

(f) DRF in the Atmosphere (online)

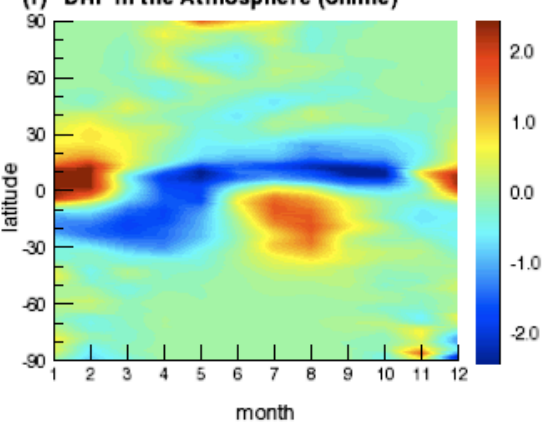

Fig. 7. Hovmöller diagrams of zonal and monthly means of differences in DRF (W/m²): (a) and (b) at the top of the atmosphere, (c) and (d) at the surface, (e) and (f) in the atmosphere due to seasonal BBCA emissions, here (a), (c), and (e) are offline results and (b), (d), and (f) are online results.

mid-level clouds ( $\triangle$ CLDMED, $4.2 \times 10^{-4}$ ), and high-level clouds $\left(\triangle \mathrm{CLDHG}, 5.6 \times 10^{-4}\right)$. The most distinct differences in total clouds are in the central Pacific Ocean, Amazon, the eastern US, West Africa, northern Africa, Indo/Himalaya, and East Asia.

For low-level clouds (Figs. 8b and 9b), the most significant positive difference ( $\triangle$ CLDLOW) appears in the northwestern coast of Africa and in the eastern US in boreal winter and spring, coinciding with the previously reported regional climate effects of biomass burning (Kaufman et al., 2005). In East Asia in boreal summer and fall and in the eastern part of Australia during boreal spring and summer, low-level clouds are lower in the seasonal run than in the non-seasonal run. These low-level clouds differences are related to the different local instability due to the aerosol effect.
For mid-level clouds (Figs. 8c and 9c), there are streaks in the shape of a fork in the central Pacific with positive differences and in the Atlantic Ocean with negative differences. Especially in the central Pacific, the clouds decrease in both BBCA emissions cases relative to no aerosol emission. Such decrease of mid-level clouds is weakened by the seasonality of BBCA emission. This phenomenon continuously occurs in the high-level cloud case (see Fig. 8d and 9d). The other large changes are in the Amazon in fall with negative differences and in Indo/Himalaya throughout the year, with positive differences. The large positive values of the difference in mid-level clouds ( $\triangle$ CLDMED) are distributed along storm tracks in the mid-latitude in boreal spring. 
(a)

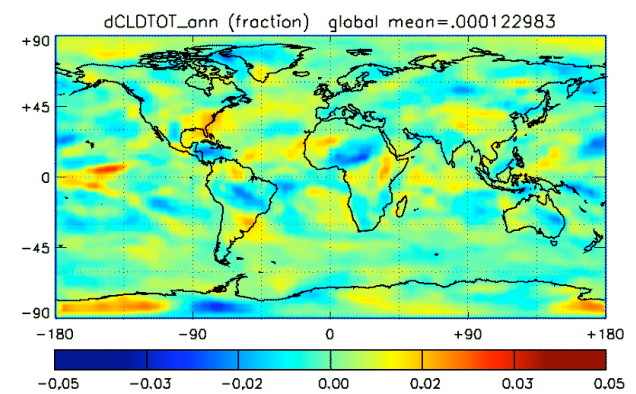

(c)

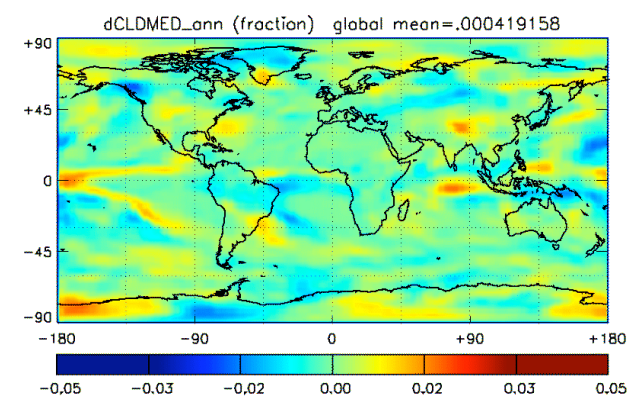

(b)

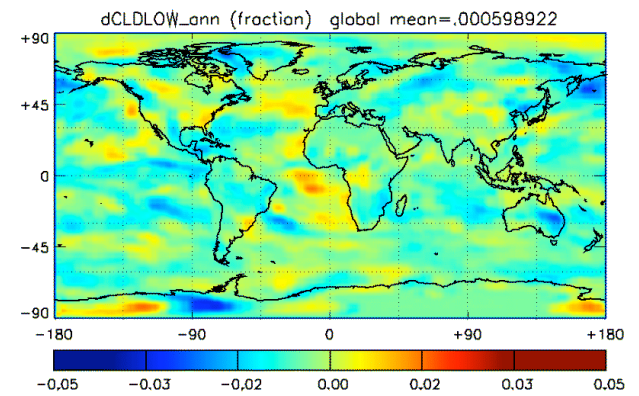

(d)

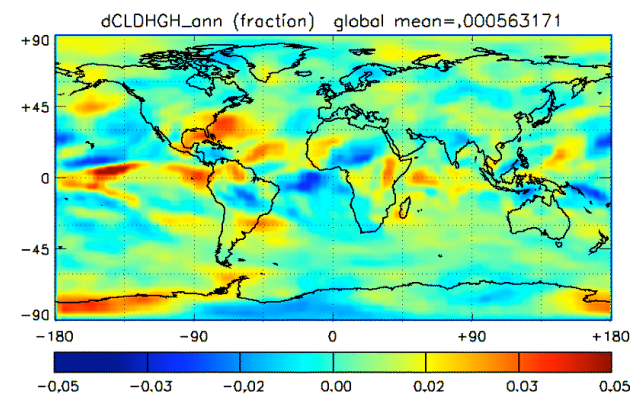

Fig. 8. Global distribution of annual mean of differences in cloud distributions due to seasonal BBCA emissions in: (a) total cloud fraction (CLDTOT), (b) low-level cloud (CLDLOW), (c) mid-level cloud (CLDMED), and (d) high-level cloud (CLDHGH).

(a)

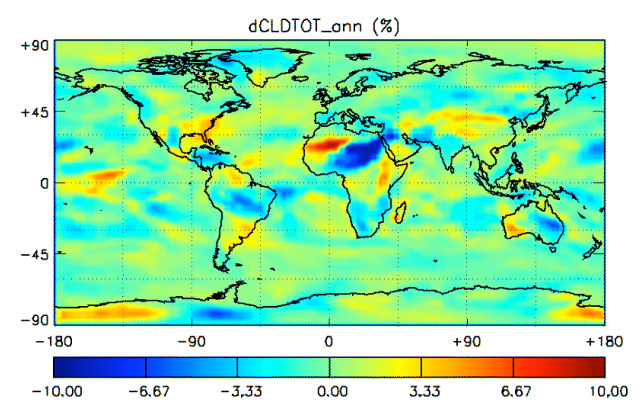

(c)

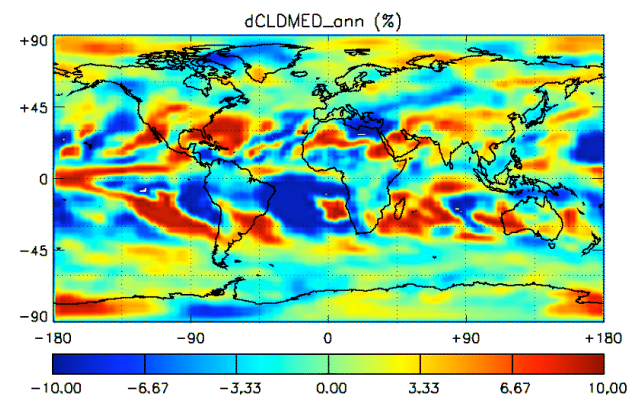

(b)

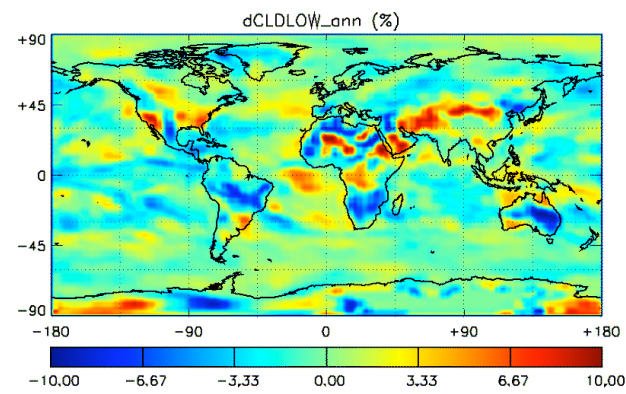

(d)

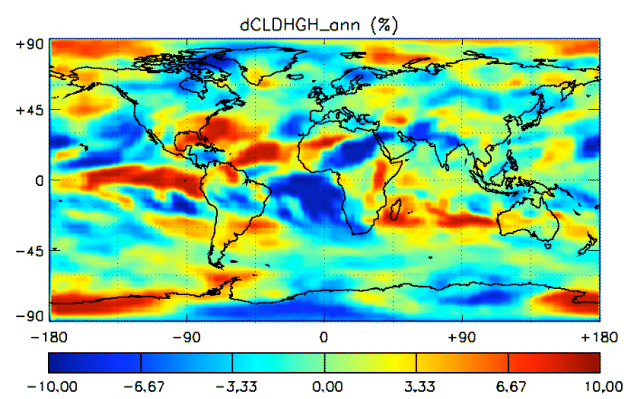

Fig. 9. Global distribution of annual mean of fractional differences in cloud distributions due to seasonal BBCA emissions in: (a) total cloud fraction (CLDTOT), (b) low-level cloud (CLDLOW), (c) mid-level cloud (CLDMED), and (d) high-level cloud (CLDHGH). 
(a)

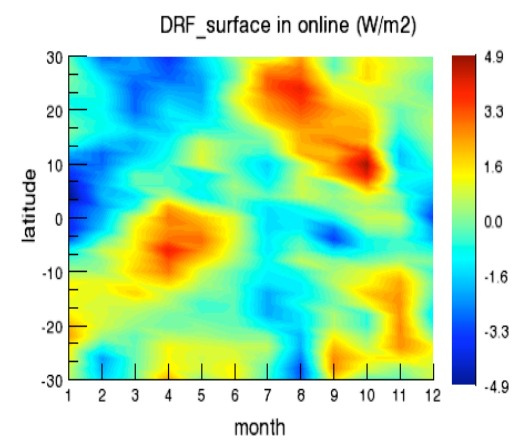

(b)

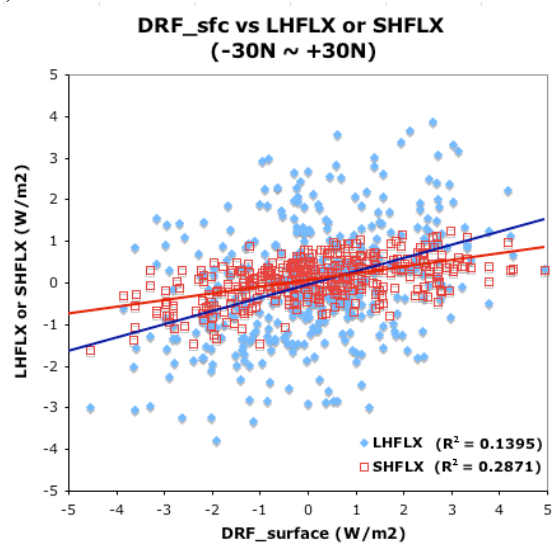

Fig. 10. (a) Hovmöller diagram of zonal monthly means in tropical region ( $30 \mathrm{~S}-30 \mathrm{~N})$ of difference in direct radiative forcing $(\triangle \mathrm{DRF})$ at the surface due to seasonal BBCA emissions. (b) The scatter plot of $\triangle \mathrm{DRF}$ at the surface against the differences in latent heat flux ( $\triangle$ LHFLX, filled blue) and sensible heat flux ( $\triangle$ SHFLX, open red). All the values are zonal monthly average over 20 years in the online runs.

In terms of high-level clouds (Fig. 8d and 9d), the differences due to BBCA emission seasonality seem to be concentrated over the ITCZ. Strong positive differences appear over the tropical central Pacific throughout the whole year except boreal summer. The negative differences appear in the Amazon, the west coast of Africa, and northern Africa and Europe in boreal winter and spring. These differences appear in low-level clouds as well as mid-level clouds. These changes may be driven by large-scale circulation because they occur apart from BBCA source regions.

We also find that the global annual or seasonal means of differences due to BBCA seasonality in sensible heat flux (SHFLX), solar heating rates (QRS), convective precipitation (PRECC), and mid-level cloud (CLDMED) are statistically significant. The global distribution of annual or seasonal means of the differences in latent heat flux ( $\triangle$ LHFLX) and the differences in sensible heat flux ( $\triangle$ SHFLX), however, do not necessarily follow the distribution pattern of the differences in $\mathrm{BC}$ column concentration $(\triangle \mathrm{BC})$ and $\mathrm{OC}$ column concentration $(\triangle \mathrm{OC})$ in biomass burning source regions. In the tropics within winter-hemisphere, the differences in the surface latent and sensible heat fluxes caused by the seasonality of BBCA are negative over biomass-burning regions, clearly attributed to the negative surface forcing of BBCA. The patterns of the zonal and monthly means of the differences in surface heat fluxes generally follow the patterns of the differences in surface aerosol direct radiative forcing ( $\triangle \mathrm{DRF}$ ) in the tropics (Fig. 10). However, the correlation between surface $\triangle \mathrm{DRF}$ and $\triangle$ LHFLX and that between surface $\triangle \mathrm{DRF}$ and $\triangle$ SHFLX in tropics as shown in Fig. 10b appear quite different: the former is poorer in comparison (much more scattered), implying that it could be affected by factors other than aerosol surface forcing. This demonstrates that through surface direct radiative forcing of aerosols, the seasonality of BBCA affects heat budget at the earth surface while the actual responses of these heat fluxes to aerosol effects differ due to other factors such as soil moisture and air humidity. The changes in surface temperature in the tropical region also exhibit a pattern similar to the two types of heat fluxes. However, the signal of temperature (regardless of surface or tropospheric values) is also affected by many factors, not necessarily locally correlated with aerosol forcing. A complex full-scale analysis of temperature change is required, but such a detailed analysis is beyond the scope of our discussion.

The zonal monthly means of differences in heat fluxes are also inversely proportional to the differences in atmospheric DRF (not shown). In addition, the zonal monthly means of the differences in atmospheric DRF are in phase with those in column averaged solar heating rates (QRS). The differences in column averaged solar heating rates $(\triangle \mathrm{QRS})$ are found to be distinct in the BBCA source regions, forming the local effect of absorbing aerosols.

The changes in solar heating rates are also caused by many other factors such as clouds and water vapor. It is difficult to separate the unique signals of heating by BBCA from the effects of other factors in the interactive aerosolclimate runs. In the upper troposphere, a clear triad negativepositive-negative pattern can be seen in the shortwave heating rate difference caused by the seasonality of BBCA distributed from the southern hemispheric to northern hemispheric tropics (Fig. 11a). This apparently reflects the difference in cloud cover caused by the BBCA seasonality. The structure is more complicated than the pair-centered structure in previous finding of BC aerosol effect (e.g., Fig. 13a, Wang 2004). In the lower troposphere, only in the southern hemisphere can one find a positive center that corresponds to the cloud cover change. The changing aerosol heating 
(a)

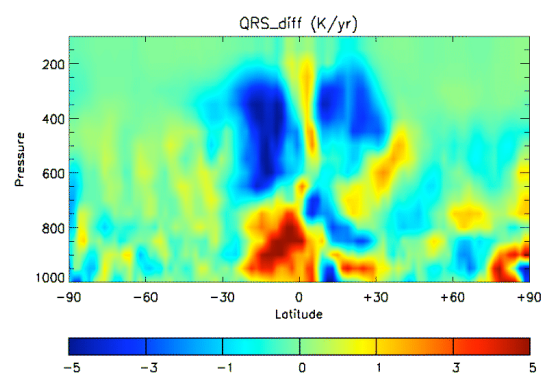

(c)

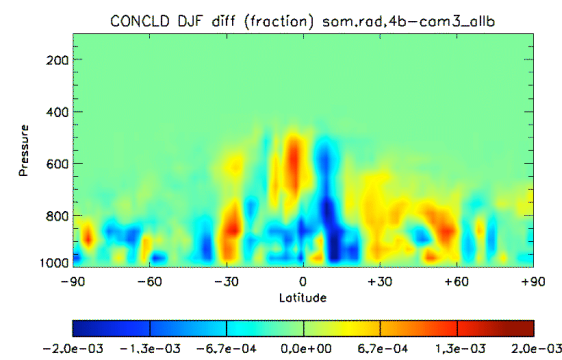

(e)

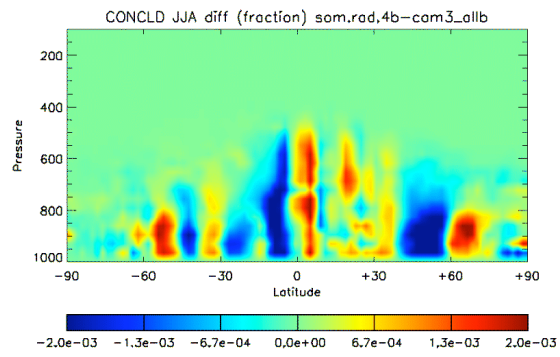

(b)

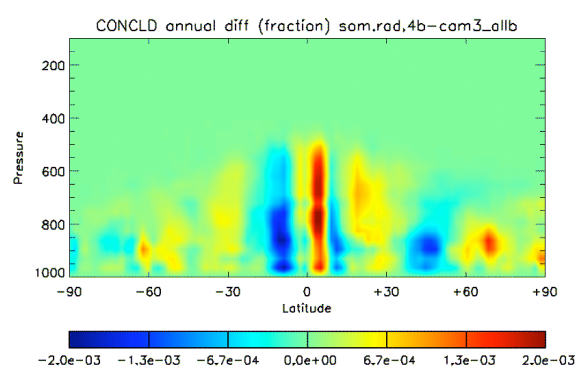

(d)

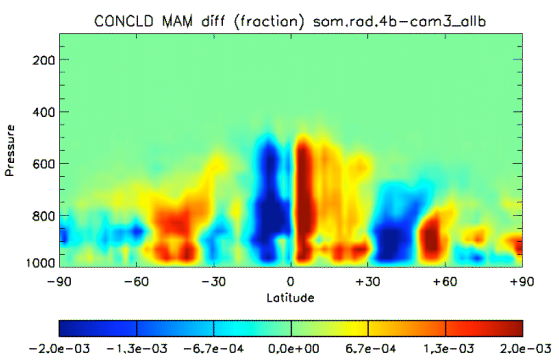

(f)

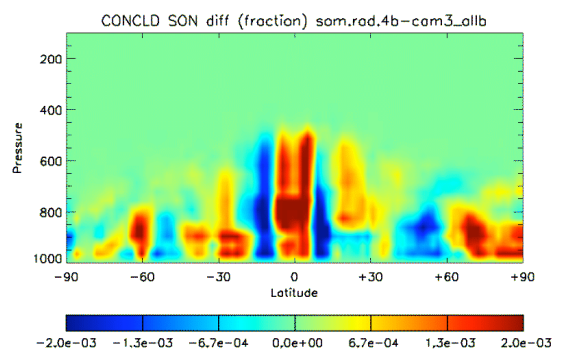

Fig. 11. Vertical cross-section of zonal and annual means of differences in: (a) solar heating rates (QRS) and (b) convective cloud fraction (CONCLD) due to the seasonality of BBCA emissions. Vertical cross-section of zonal and seasonal means of differences in convective cloud fraction (CONCLD) in: (c) DJF, (d) MAM, (e) JJA, and (f) SON, due to the seasonality of BBCA emissions.

effects due to BBCA seasonality, on the other hand, is represented by several smaller centers with positive or negative signs mostly in the lower troposphere of the northern hemisphere.

The triad-center structure can be also found in the difference in annual convective clouds ( $\triangle$ CONCLD; Fig. $11 b$ ), further implying a complicated impact on the convection and precipitation distributions in ITCZ. Seasonal analyses are thus needed to better understand this impact. From the zonalseasonal mean of TOA radiative forcing difference caused by BBCA seasonality (Fig. 7), we can find that the forcing difference between the seasonal run and non-seasonal run appears to be: 1) positive (warming) in the northern hemisphere (NH) and negative (cooling) in the southern hemisphere (SH) during December-January-February (DJF); 2) cooling in both hemispheres but more extensive in the SH during March-April-May (MAM); 3) cooling NH while warming in the SH during June-July-August (JJA); and 4) cooling in the
NH during September-October-November (SON). Based on previous analyses (e.g., Wang, 2004, 2007, 2009), aerosolinduced positive (negative) TOA forcing in the northern hemisphere could lead to a northward (southward) shift of ITCZ. The TOA forcing features revealed in Fig. 7a due to BBCA seasonality would create a northward shift of ITCZ convective precipitation band in DJF and MAM and an opposite shift in JJA and SON. These are generally consistent with the results of seasonal convective cloud cover even though the change pattern is not very clear in DJF (Fig. 11c-f; note that the positive difference of convective cloud in JJA close to the equator in the $\mathrm{NH}$ actually represents a southward switch because the heavy precipitation band should be in further north in this season).

In an annual mean base, the differences in convective precipitation $(\triangle \mathrm{PRECC})$ caused by the seasonality of BBCA would be equivalent to a southward switch over the central and eastern Pacific while oppositely over the Atlantic 
(a)

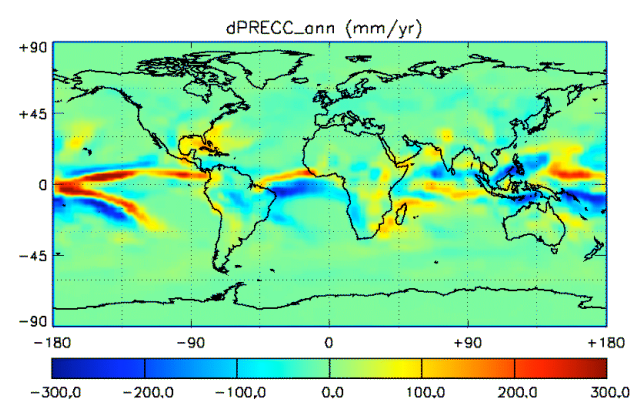

(c)

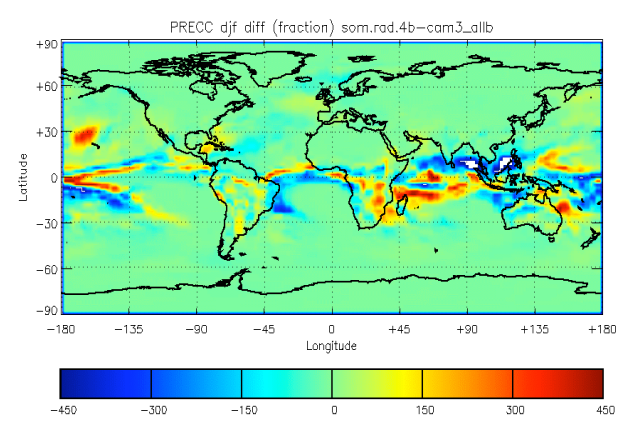

(e)

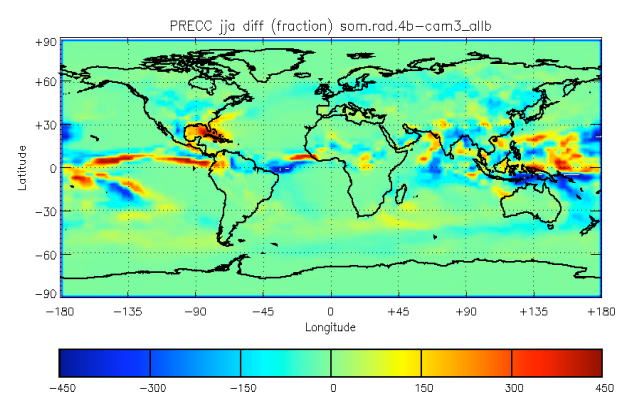

(g)

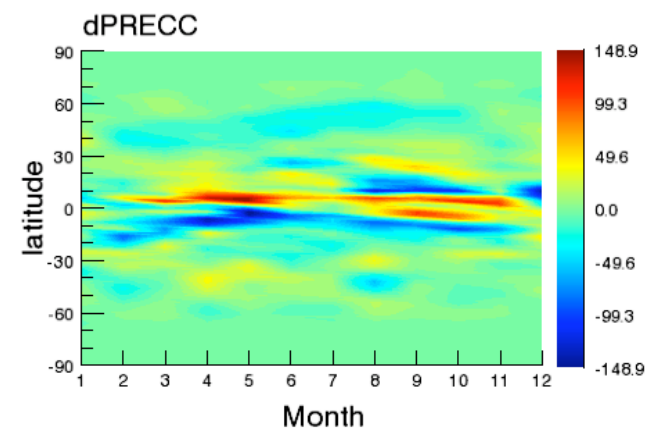

(b)

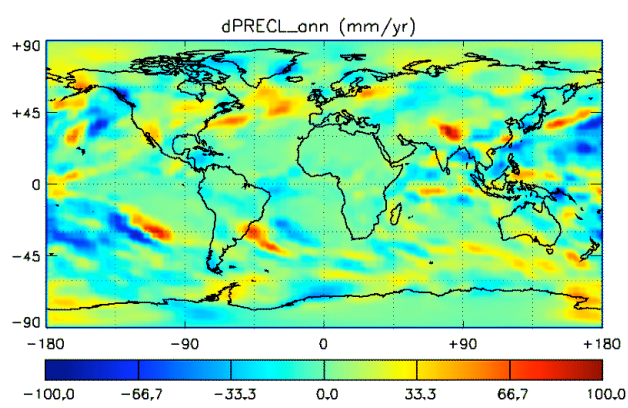

(d)

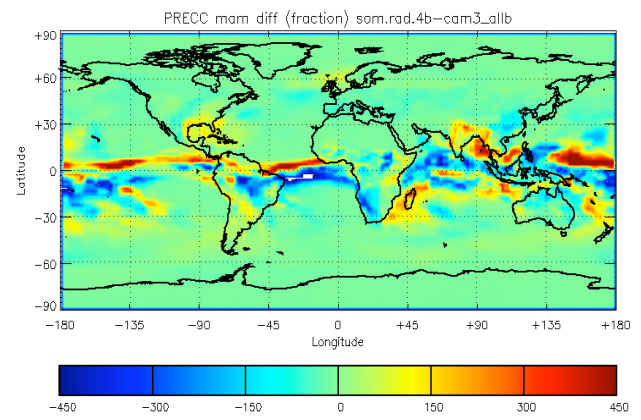

(f)

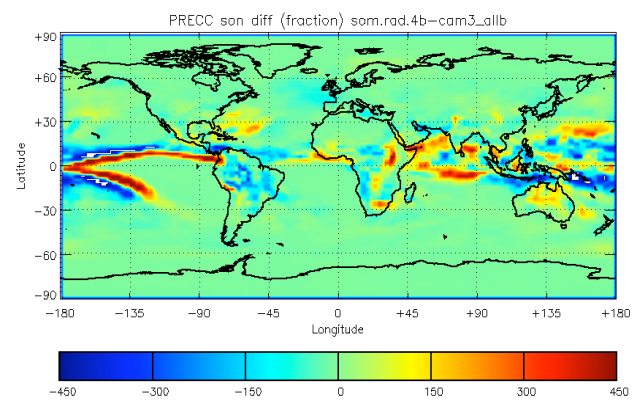

(h)

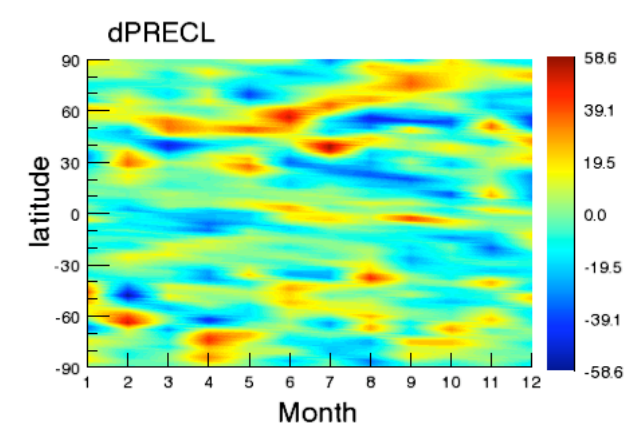

Fig. 12. Global distribution of annual mean of differences in precipitation due to seasonal BBCA emissions, (a) convective precipitation (PRECC) and (b) large scale precipitation (PRECL). Global distribution of seasonal means of differences in convective precipitation due to seasonal BBCA emissions in: (c) DJF, (d) MAM, (e) JJA, and (f) SON. Also shown are Hovmöller diagrams of zonal monthly means of differences in precipitation, (g) PRECC and (h) PRECL, due to seasonal BBCA emissions. 
(Fig. 12a). A northward shift of the Hadley cell was suggested as a net warming effect caused by absorbing aerosols in the northern hemisphere when only annually constant emissions of biomass burning and fossil fuel $\mathrm{BC}$ were used (e.g. Wang, 2004, 2007). In this study, however, biomassburning-emitted aerosols include both scattering organic carbon (external OC and internal mixture of OC and sulfate) and absorbing aerosols (external $\mathrm{BC}$ and internal mixture of $\mathrm{BC}$ and sulfate). In addition, the biomass-burning regions are mostly close to the equator, in contrast to the case of fossil fuel carbonaceous aerosols that are dominant in the northern hemispheric mid-latitude. All these have complicated the BBCA impact on the large-scale dynamics, in particular the convection and precipitation in the ITCZ. The seasonal-mean of difference in convective precipitation due to the seasonality of BBCA exhibits complicated regional distributions. Over the central and eastern Pacific, the convective precipitation in ITCZ experiences a southward enhancement in all seasons except MAM (Fig. 12c-f). Over the Atlantic, however, convective precipitation exhibits an equivalent northward shift in all except MAM seasons if seasonality of BBCA is considered compared to the case otherwise. The Hovmöller diagram of convective precipitation difference due to the seasonality of BBCA (Fig. 12g) further demonstrates the same feature, where through JJA and SON, convective precipitation difference around the equator displays a triad band structure with negative, positive, and negative signs from southern hemispheric tropics to northern hemispheric tropics, representing a southward shift of ITCZ convective precipitation. The MAM result is the opposite of the above time period. Similar to the result of convective cloud cover (Fig. 11), the difference in DJF convective precipitation due to BBCA seasonality is not clearly defined in a zonal mean base.

On the other hand, the difference in large-scale precipitation $(\triangle \mathrm{PRECL})$ can be observed over storm tracks in the mid-latitude (Fig. 12b, h). This is the same location where the second type of noticeable differences in convective cloud occurs. The global distribution of the annual mean of $\triangle$ PRECL shows large positive values in Europe and the North Atlantic Ocean when the differences in most aerosol column loadings are negative.

As displayed in the Hovmöller diagram, the patterns of the zonal monthly means of the differences in convective precipitation and large-scale precipitation (Fig. 12g, h) are not clearly correlated with those of the differences in aerosol direct radiative forcing (Fig. 7) as well as BC column concentration or OC column concentration. The pattern of the large differences in convective precipitation lies along the ITCZ, which is very similar to the patterns of the differences in the high-level cloud fraction. The positive and negative differences distributed along the tropics in the northern hemisphere and southern hemisphere, respectively - which correspond to decreased convection due to biomass emission and thus anomalous effects that the Hadley cell shifts - appear almost statically throughout the entire year. The distributions of the differences in both types of precipitation reach regions far beyond the biomass burning regions, clearly implying that BBCA aerosols affect global atmospheric circulation.

\section{Conclusions}

We have investigated the climatic effects of seasonal biomass burning emitted carbonaceous aerosols (BBCA) emissions using 60-year simulations of the 3-D aerosol-climate model with two sets of BBCA emission data that respectively include and exclude the seasonality of BBCA emissions. "Seasonal BBCA climate forcing" or "seasonal BBCA effects" were derived from the differences in direct radiative forcing (DRF) of aerosols or other climate variables between the results of these two runs.

The seasonality of BBCA emissions leads to an increase in the external mixture of carbonaceous aerosols as well as the homogeneous mixture of OC and sulfate (MOS), and a decrease in the core-shell mixtures of BC and sulfate (MBS), relative to those in constant annual BBCA emissions. We find that the differences in atmospheric direct radiative forcing (DRF) caused by BBCA seasonality are in phase with the differences in column concentrations of external mixture of carbonaceous aerosols in space and time. In contrast, the differences in all-sky radiative forcing at TOA and at the surface extend beyond the BBCA source regions due to climate feedback through cloud distribution and precipitation.

Such global and seasonal distributions of differences in climate forcing induce significant differences in climate variables. These differences appear in places beyond the biomass burning regions and last longer than the biomass burning seasons. This finding is best demonstrated by the differences in convective cloud fraction and convective precipitation caused by the seasonality of BBCA emissions, in an annual mean base which is represented by a pattern corresponding to a southward shift of the Pacific ITCZ and a northward shift of the Atlantic ITCZ while the detailed seasonal features are much more complicated. The differences in precipitation are actually maxima in boreal spring but minima in boreal winter. The differences in aerosol transformation due to the seasonality of BBCA emissions are clearly shown in mixed aerosols in boreal spring.

Such a difference in terms of temporal distribution may also introduce positive feedback into the BBCA aerosolclimate interaction. These results suggest that excluding the seasonality of BBCA from the climate model could produce a significant artifact in modeled aerosol effects on climate, even if the analysis is done on an annual-mean basis. 


\section{Supplementary material related to this article is available online at: http://www.atmos-chem-phys.net/10/8373/2010/ acp-10-8373-2010-supplement.pdf.}

Acknowledgements. We thank Dongchul Kim for assisting in the model setup and data processing, NCAR for providing the CAM code, and the GEIA project for providing emission data. This research is supported by the NASA IDS (NNX07AI49G), the NSF (ATM-0329759), and the MIT Joint Program on the Science and Policy of Global Change.

Edited by: V. F. McNeill

\section{References}

Bevan, S. L., North, P. R. J., Grey, W. M. F., Los, S. O., and Plummer, S. E.: Impact of atmospheric aerosol from biomass burning on Amazon dry-season drought, J. Geophys. Res., vol. 114, D09204, doi:10.1029/2008JD011112, 2009.

Bond, T. C., Streets, D. G., Yarber, K. F., Nelson, S. M., Woo, J., and Klimont, Z.: A technology-based global inventory of black and organic carbon emissions from combustion, J. Geophys. Res., 109, D14203, doi:10.1029/2003JD003697, 2004.

Boville, B. A., Rasch, P. J., Hack, J. J., and McCaa, J. R.: Representation of Clouds and Precipitation Processes in the Community Atmosphere Model Version 3 (CAM3), J. Clim., 19, 2184-2198, 2006

Chou, C., Neelin, J. D., Lohmann, U., and Feichter, J.: Local and Remote Impacts of Aerosol Climate Forcing on Tropical Precipitation, J. Clim., 18, 4621-4635, 2005.

Collins, W. D., and Bitz, C. M., Blackmon, M. L. Bonan, G. B., Bretherton, C. S., Carton, J.A., Chang, P., Doney, S. C., Hack, J. J., Henderson, T. B., Kiehl, J. T., Large, W. G., Mckenna, D. S., Santer B. D., and Smith, R. D.: The Community Climate System Model Version 3 (CCSM3), J. Clim., 19, 2122-2143, 2006.

Cooke, W. F. and Wilson, J. J. N.: A global black carbon aerosol model. J. Geophys. Res., 101, 14, 19395-19409, 1996.

Cooke, W. F., Koffi, B., and Gregoire, J.-M.: Seasonality of vegetation fires in Africa from remote sensing data and application to a global chemistry model. J. Geophys. Res., 101, 15, 2105121065, 1996.

Crutzen, P. J. and Andreae, M. O.: Biomass Burning in the tropics: Impact on Atmospheric Chemistry and Biogeochemical Cycles, Science, 250, 1669-1678, 1990.

Feingold, G., Jiang, H., and Harrington, J. Y.: On smoke suppression of cloud in Amazonia, Geophy. Res. Lett., 32, L02804, doi:10.1029/2004GL021369, 2005.

Forster, P., Ramaswamy, V., Artaxo, P., et al.: Changes in Atmospheric Constituents and in Radiative Forcing. In: Climate Change 2007: The Physical Science Basis. Contribution of Working Group I to the Fourth Assessment Report of the Intergovernmental Panel on Climate Change, edited by: Solomon, S., Qin, D., Manning, M., et al. Cambridge University Press, Cambridge, UK and New York, NY, USA, 129-234, 2007.

GEIA biomass burning BC data: http://www.geiacenter.org/, last access: 30 April 2008 .
Hack, J. J., Caron, J. M., Yeager, S. G., Oleson, K. W., Holland M. M., Truesdale, J. E., and Rasch, P. J.: Simulation of the Global Hydrological Cycle in the CCSM Community Atmosphere Model Version 3 (CAM3): Mean Features. J. Clim., 19, 2199-2221, 2006.

Hao, W. M., Liu, M. H., and Crutzen, P. J.: Estimation of annual regional releases of $\mathrm{CO}_{2}$ and other trace gases to the atmosphere from fires in the tropics, based on the FAO statistics for the period 1975-1989. In: Fire in the Tropical Biota: J. G. Goldammer, Springer-Verlag, Berlin, Heidelberg, Germany, 440-462, 1990.

Hurrell, J. W., Hack, J. J., Phillips, A. S., Caron, J., and Yin, J.: The Dynamical Simulation of the Community Atmosphere Model Version 3 (CAM3), J. Clim., 19, 2162-2183, 2006.

Kaufman, Y. J., Koren, I., Remer, L. A., Rosenfeld, D., and Rudich, Y: The effect of smoke, dust, and pollution aerosol on shallow cloud development over the Atlantic Ocean, Proc. Natl. Acad. Sci., USA, 102, 11207-11212, 2005.

Kim, D., Wang, C., Ekman, A. M. L., Barth, M. C., and Rasch, P.: Distribution and direct radiative forcing of carbonaceous and sulfate aerosols in an interactive size-resolving aerosol-climate model, J. Geophys. Res., 113, D16309, doi:10.1029/2007JD009756, 2008.

Kinne, S., Lohmann, U., Feichter, J., Schulz, M., Timmreck, C., Ghan, S., Easter, R., Chin, M., Ginoux, P., Takemura, T., Tegen, I., Koch, D., Herzog, M., Penner, J., Pitari, G., Holben, B., Eck, T., Smirnov, A., Dubovik, O., Slutsker, I., Tanre, D., Torres, O., Mishchenko, M., Geogdzhayev, I., Chu, D. A., and Kaufman, Y.: Monthly averages of aerosol properties: A global comparison among models, satellite data, and AERONET ground data, J. Geophys. Res., 108(D20), 4634, doi:10.1029/2001JD001253, 2003.

Koren, I., Kaufman, Y. J., Remer, L. A., and Martins, J. V.: Measurement of the Effect of Amazon Smoke on inhibition of Cloud formation, Science, 303, 1342, doi:10.1126/science.1089424, 2004.

Koren, I., Martins, J. V., Remer, L. A., and Afargan, H.: Smoke invigoration Versus Inhibition of Clouds over Amazon, Science, 321, 946, doi:10.1126/science.1159185, 2008.

Krishnan, R. and Ramanathan, V.: Evidence of surface cooling from absorbing aerosols, Geophy. Res. Lett., 29(9), 54, doi:10.1029/2002GL014687, 2002.

Lin, J. C., Matsui, T., Pielke, R. A., and Kummerow, C.: Effects of biomass-burning-derived aerosols on precipitation and clouds in the Amazon Basin: a satellite-based empirical study, J. Geophys. Res., 111, D19204, doi:10.1029/2005JD006884, 2006.

Martins, J. A., Silva Dias, M. A. F., and Gonçalves, F. L. T.: Impact of biomass burning aerosols on precipitation in the Amazon: I. A modeling study, J. Geophys. Res., 114, D02207, doi:10.1029/2007JD 009587, 2009.

Menon, S. and Del Genio, A. D.: Evaluation the impacts of carbonaceous aerosols on clouds and climate, in: humanInduced Climate Change: Interdisciplinary Assessment, edited by: Schlesinger, M. E., Kheshgi, H. S., Smith, J., et al., Cambridge University Press, Cambridge, UK, 2007.

Menon, S.: Current Uncertainties in Assessing Aerosol Effects on Climate, Ann. Rev. Environ. Resour., 29, 1-30, doi:10.1146/annurev.energy.29.063003.132549, 2004.

Menon, S., Unger, N., Koch, D., Francis, J., Garrett, T., Sednev, I., Shindell, D., and Streets, D.: Aerosol climate effects and 
air quality impacts from 1980 to 2030, Environ. Res. Lett., 3, 024004, doi:10.1088/1748-9326/3/2/024004, 2008.

Menon, S., Hansen, J., Nazarenko, L., and Luo, Y.: Climate effects of Black Carbon Aerosols in China and India, Science, 297, 2250, doi:10,1126.science.1075159, 2002.

Paltsev, S., Reilly, J. M., Jacoby, H. D., Eckaus, R. S., McFarland, J., Sarofim, M., Asadoorian, M., and Babiker, M.: The MIT Emissions Prediction and Policy Analysis (EPPA) Model: Version 4, Joint Program Report Series (August), 2005.

Ramaswamy, V., Boucher, O., Haigh, J., et al.: Radiative Forcing of Climate Change. In: Climate Change 2001: The Scientific Basis. Contribution of Working Group I to the Third Assessment Report of the Intergovernmental Panel on Climate Change, Houghton, J. T., Ding, Y., Griggs, D. J., et al., Cambridge Univ. Press, UK, 353, 2001.

Ramanathan, V. and Carmichael, G.: Global and regional climate change due to black carbon, naturegeoscience, 1. 221-227, April 2008.

Ramanathan, V., Chung, C., Kim, D., Bettge, T., Buja, L., Kiehl, J. T., Washington, W. M., Fu, Q., Sikka, D. R., and Wild, M.: Atmospheric brown clouds: Impacts on South Asian Climate and hydrological cycle, Proc. Natl. Acad. Sci., USA, 102(15), 53265333, 2005.

Roeckner, E., Stier, P., Feichter, J., Kloster, S., Esch, M., and Fischer-Bruns, I.: Impact of carbonaceous aerosol emissions on regional climate change, Clim. Dynam., 27, 553-571, doi:10.1007/s00382-006-0147-3, 2006.

Rosenfeld, D., Lohmann, U., Raga, G. B., O’Dowd, C. D., Kulmala, M., Fuzzi, S., Reissell, A., and Andreae, M. O.: Flood or Drought: How Do Aerosols Affect Precipitation?, Science, doi:10.1126/science.1160606, 321, 1309-1313, 2008.

Rosenfeld, D.: TRMM Observed First Direct Evidence of Smoke from Forest Fires Inhibiting Rainfall, Geophys. Res. Lett., 26(20), 3105-3108, 1999.
Rotstayn, L. D. and Lohmann, U.: Tropical Rainfall Trends and the Indirect Aerosol Effect, J. Clim., 15, 2103-2116, 2002.

Schultz, M. G., Heil, A., Hoelzemann, J. J., Spessa, A., Thonicke, K., Goldammer, J., Held, A. C., Pereira, J. M., and van het Bolscher, M.: Global Wildland Fire Emissions from 1960 to 2000, Global Biogeochem. Cy., 22, GB2002, doi:10.1029/2007GB003031, 2008.

van der Werf, G. R., Randerson, J. T., Giglio, L., Collatz, G. J., Kasibhatla, P. S., and Arellano Jr., A. F.: Interannual variability in global biomass burning emissions from 1997 to 2004, Atmos. Chem. Phys., 6, 3423-3441, doi:10.5194/acp-6-3423-2006, 2006.

Wang, C.: A modeling study on the climate impacts of black carbon aerosols, J. Geophys. Res., 109, D03106, doi:10.1029/2003JD004084, 2004.

Wang, C.: Impact of direct radiative forcing of black carbon aerosols on tropical convective precipitation, Geophys. Res. Lett., 34, L05709, doi:10.1029/2006GL028416, 2007.

Wang, C.: The sensitivity of tropical convective precipitation to the direct radiative forcings of black carbon aerosols emitted from major regions, Ann. Geophys., 27, 3705-3711, doi:10.5194/angeo-27-3705-2009, 2009.

Wang, C., Jeong, G. R., and Mahowald, N.: Particulate absorption of solar radiation: anthropogenic aerosols vs. dust, Atmos. Chem. Phys., 9, 3935-3945, doi:10.5194/acp-9-3935-2009, 2009.

Zhang, M. H., Lin, W. Y., Klein, S. A., Bacmeister, J. T., Bony, S., Cederwall, R. T., Del Genio, A. D., Hack, J. J., Loeb, N. G., Lohmann, U., Minnis, P., Musat, I., Pincus, R., Stier, P., Suarez, M. J., Webb, M. J., Wu, J. B., Xie, S. C., Yao, M.-S., and Zhang, J. H.: Comparing clouds and their seasonal variations in 10 atmospheric general circulation models with satellite measurements, J. Geophys. Res., 110, D15S02, doi:10.1029/2004JD005021, 2005. 